\title{
Introduction: Permitted but unauthorised
}

use

\section{Jeremy Phillips}

\section{WHAT IS MEANT BY 'PERMITTED BUT UNAUTHORISED USE'?}

Trade mark law confers upon the proprietor of a registered trade mark a very wide power over other traders who use his trade mark. Put simply, if that use is without the proprietor's permission, the proprietor has the power to prohibit it by bringing a legal action against the user for infringement. If however that use is with the proprietor's permission, he may make that use conditional upon such terms as he seeks to impose.

The reality is less simple. This is because there is a category of use that the trade mark owner is powerless to prevent: use which, while lacking the proprietor's authorisation, is nonetheless permitted by the law. More accurately, there are several different categories of use that the law tolerates, whatever the feelings of the trade mark owner. Some of these uses are based on commercial imperatives, such as a retailer's need to be able to inform consumers about the goods he sells; others are based on political imperatives, such as the exercise of the human right of freedom of speech; others again are based on considerations of honesty or fairness, such as where a trader seeks to trade under his own name even though that name is the same as, or similar to, an earlier registered trade mark.

\section{STRIKING A BALANCE}

In each of the instances in which the law permits the use of a trade mark even where that mark's owner does not authorise it, it is plain that the law has sought to establish a balance between the interests of the trade mark owner and those of others. In some cases the balance is sought between the trade mark owner and a direct competitor; in other cases it may be sought between him and those whose business interests lie downstream of his own (such as distributors and retailers), the consumer of his goods or even the public at large. 
Wherever a balance is sought, it is necessary to identify the point at which the competing or conflicting interests are in equilibrium. Too much protection for the trade mark owner may mean that others cannot refer to the mark when critically comparing products sold under it with those of other products; too little protection may mean erosion of the trade mark's ability to provide consumers with a confident guarantee that its use indicates the identity of the origin of goods or services for which it is used.

The technique provided by legislators the world over is the same. Since it is impossible to predict the precise circumstances in which the valuable role of a trade mark is threatened, and it is equally impossible to anticipate the circumstances in which its enforcement may be oppressive, general principles are enacted into law. It is then left to the courts or other tribunals to interpret those general principles in the light of specific sets of facts in which the interests of trade mark proprietor and unauthorised user collide.

\section{THE TENSIONS OF TRADE MARK LAW}

It is now no longer doubted that the right conferred by trade mark registration is a property right. This is something that is explicitly stated in the trade mark legislation of most countries and which has been backed by a ruling of the European Court of Human Rights in 11 October 2005 in Case 73049/01 Anheuser-Busch Inc. v Portugal.

Many property rights are vulnerable to exceptions or limitations in favour of third parties, even where the property right owner withholds his authorisation. Thus, in respect of real property such as land, the right to exclude others may be exercised against casual acquaintances or passers-by, but will not enable the rights owner to bar access to, for example, the police authorities or the emergency fire services. Other third party users may include members of the public who have a right of way. The enforcement of intellectual property rights is likewise diminished by the ability of third parties to 'invade' the rights owner's intellectual estate and to do so against his will. Patent, trade mark and copyright law make ample provision for such use.

The analogy between real property and intellectual property is however an imperfect one. This is because the unauthorised but permitted use of land or other real property is unlikely to destroy its value completely while, in the case of a trade mark, permitted third party use can result in the goodwill in the mark being wiped out (as where one branded product is compared highly unfavourably with another). Nor does the analogy with land convey the risk that a trade mark will cease to be able to inform consumers of the origin of goods or services marketed under it (as happens where the honest use of a confusingly similar mark cannot be restrained). The vulnerability of trade 
marks to diminution of their value or their power may be more fully appreciated when one considers the very wide range of uses to which a trade mark may be put and which do not even fall within the scope of trade mark infringement at all. For example, it is not an infringement of a trade mark for a large number of consumers to opt to refer to their vacuum cleaners as hoovers or for the media and the medical profession to describe acquired immune deficiency syndrome as AIDS, thus rendering commercially useless several trade marks for slimming products. But these uses lie outside the scope of this volume.

\section{THIS BOOK}

Trade Marks at the Limit examines the points at which trade mark rights reach the limits of their enforceability. In doing so, it seeks to set out the general framework within which the balance of competing interests is attained. Subsequent chapters consider areas in which specific problems arise, also contrasting the European approach with those of the United States and Australia. Finally, the book addresses some broader issues. One is theoretical (is it in some way better for a business not to rely upon the unauthorised but permitted use of the marks of others) and two are practical (how does third party use affect a trade mark's valuation and what steps can a trade mark proprietor take to minimise any unwanted effects of such use?).

This book is not intended to be a text book or a practitioners' manual. At one level it is a collaborative snap-shot of the law and practice as it stands, as viewed from the perspective of a band of authors who all work extensively within the field of trade mark law and branding practice and who care greatly about how the system works. Yet it is also more than that: the chapters treat their appointed topics to a greater deal of in-depth analysis than most judges, authors of textbooks and professional treatises are able to justify when addressing trade mark law as a whole. Speculative issues are investigated as well as matters of persistent concern. Questions are asked even when there is no easy answer - or no answer at all.

In this book the reader may find more questions asked than answers given, but that should be viewed as a positive advantage. Particularly in European law, where the norms of a relatively newly-approximated system are still 'bedding down', uncertainties are bound to remain unresolved. Some of these uncertainties are being addressed by references made to the Court of Justice of the European Communities. Other uncertainties are being left unresolved (for example the interplay of the trade mark right and the rights of political and commercial free speech) because many businesses may be content to live with the flexibilities that uncertainties present than an adverse result in their resolution. 
In publishing this collection of essays, the editor and authors join in hoping that they will at least have done something to sensitise readers to some of the complexities of the issues that are involved when delineating the limit beyond which a trade mark owner may not interfere with the use that others make of his trade mark. This is an area in which further debate is inevitable. We all hope that this debate will be well-informed and that we will, through the medium of this book, have contributed to it. 